\section{Mundo Rerutate de} QgraIC issw isismos
Mundo Agrario

ISSN: 1515-5994

mundoagrario@fahce.unlp.edu.ar

Universidad Nacional de La Plata

Argentina

\title{
La representación de intereses de la cúpula del sector agropecuario. La Sociedad Rural Argentina (1996-2008)
}

\author{
Panero, Marcelo Oscar \\ La representación de intereses de la cúpula del sector agropecuario. La Sociedad Rural Argentina \\ (1996-2008) \\ Mundo Agrario, vol. 21, núm. 46, 2020 \\ Universidad Nacional de La Plata, Argentina \\ Disponible en: http://www.redalyc.org/articulo.oa?id=84562590002 \\ DOI: https://doi.org/10.24215/15155994e135
}

Esta obra está bajo una Licencia Creative Commons Atribución-NoComercial-Compartirlgual 4.0 Internacional. 


\section{La representación de intereses de la cúpula del sector agropecuario. La Sociedad Rural Argentina (1996-2008)}

The representation of interests of the agricultural economic elite. The Argentine Rural Society (1996-2008)

Marcelo Oscar Panero

Universidad Nacional de General Sarmiento, Argentina

DOI: https://doi.org/10.24215/15155994e135

mpanero@campus.ungs.edu.ar

Redalyc: http://www.redalyc.org/articulo.oa?id=84562590002

Recepción: 10 Marzo 2019

Aprobación: 15 Agosto 2019

\section{RESUMEN:}

Es objetivo de este artículo abordar la representación de intereses de la cúpula agropecuaria argentina, luego de los cambios ocurridos desde fines del siglo XX. Para ello, se analiza la Sociedad Rural Argentina (SRA) entre 1996 y 2008.

Sobre la base de datos cuantitativos, análisis de material institucional y entrevistas a dirigentes, socios e informantes clave, se constató que SRA exhibió un alto grado de inercia institucional. Ello le permitió permanecer como representante de la fracción más tradicional de la cúpula del agro argentino, a la vez que implicó la pérdida de centralidad representativa que tuvo durante buena parte del siglo XX.

Palabras ClaVE: Empresarios, Corporativismo, Agro, Elite económica, Sociedad Rural Argentina.

\section{Abstract:}

This paper addresses the interest's representation of the agricultural economic elite in Argentina, after transformations ocured since the end of XX century. In order to acomplish that, the Argentinian Rural Society (SRA) is analyzed between 1996 and 2008. Based on quantitative data, institutional information and interviews with leaders, members and key informants, it can be showed that SRA exhibits a high degree of institutional inercia. This has allowed it to remain as representative of the most tradtional fraction in argentinian agricultural activity. At the same time, it supposed the lost of its centrality, which had been a distinctive characteristic of the SRA in most of the XX century

KEYWORDS: Business owners, Corporatism, Agricultural, Economic Elite, Argentinian Rural Society.

\section{INTRODUCCIÓN}

Este artículo tiene como objetivo hacer un aporte al conocimiento de la temática de la representación de intereses sectoriales y, más específicamente, sobre lo ocurrido con los actores representativos tradicionales/ históricos ${ }^{1}$ luego de los cambios económicos, políticos y sociales acaecidos en la Argentina en las últimas décadas del siglo XX. En particular, se centrará en la representación de intereses de la fracción del empresariado agropecuario que conforma la cúpula del sector en la Argentina. Para ello, se analizará la entidad representativa más antigua de dicho ámbito, Sociedad Rural Argentina (SRA), durante el período 1996 $-2008 .^{2}$

Desde su nacimiento en 1866, esta entidad ha estado emparentada con los intereses de los más grandes propietarios del sector, principalmente aquellos situados en la provincia de Buenos Aires; ha dado un lugar prioritario a la defensa de los intereses ganaderos y se referencia con los productores de más antigua data en la actividad agropecuaria. Más allá de algunos cambios, esta caracterización no sufrió grandes alteraciones durante buena parte del siglo XX y así lo han reflejado, o permiten entreverlo, distintas investigaciones (Newton, 1966; de Imaz, 1964; Zemborain, 1973; Sidicaro, 1982; Ferrer, 1986; Smith 1986; Gallo, Cortés Conde, 1986; Martínez Nogueira, 1988; Palomino, 1987, 1988; Boveri y Lozada de Palma, 1994; Hora, 2002, 2005; Barsky y Gelman, 2005; Tarruella, 2012; entre otros). 
Hacia 1983, con el retorno de la democracia, la Argentina asistió a una modificación de su régimen político. Iniciados los 90, se produjeron significativos cambios en la economía, en el tipo de inserción del país en el mundo y en la estructura estatal. Tales cambios incidieron sobre las instancias que conforman la actividad representativa: las bases sociales de diferentes sectores, las características del destinatario de las demandas sectoriales y los canales de acceso al mismo, así como sobre los actores representativos. En ese marco, se abrieron interrogantes en el campo de las investigaciones sociales y políticas acerca de lo que sucedía con la representación de intereses en distintos ámbitos y los diferentes actores representativos. Dentro de dichos interrogantes, una serie de trabajos indagó acerca de lo ocurrido con los actores representativos tradicionales/ históricos, tanto en el ámbito partidario electoral como en el sindical y el empresarial. En esta línea de preocupaciones se inscribe el presente artículo.

Dichas investigaciones pudieron observar cómo distintas estrategias llevadas adelante por los actores tuvieron como corolario diferentes resultados en cuando a su permanencia en tanto representantes. Así, Torre (2003) observó que la Unión Cívica Radical (UCR) sufrió un proceso de declive en su capacidad representativa con posterioridad a 1983, en tanto el Partido Justicialista (PJ) logró conservar su competitividad electoral. En la misma línea, Levitsky (2005) ahondó en los cambios que le permitieron al PJ ser exitoso en su permanencia. Para el caso de los sindicatos, Murillo (1997), Palomino (1995), Pereyra (2008), Etchemendy (2001), entre otros, abordaron diferentes experiencias en las que predominaron reconversiones institucionales, lo que les permitió mantenerse como actores de relevancia luego de los cambios. En el ámbito empresarial, Heredia (2003) analizó el caso de la Asociación de Bancos de la Argentina (ADEBA), que, mediante un fuerte proceso de renovación institucional, logró permanecer como representante del sector financiero. Dossi (2009), en tanto, tomó el caso de la Unión Industrial Argentina (UIA), la cual desplegó distintas estrategias sin una reconversión de la institución, que le permitieron permanecer como la representante principal de los intereses industriales en la Argentina.

El sector agropecuario no sólo se vio afectado por los mencionados cambios en el régimen político, en la macroeconomía y en la estructura estatal. Además, asistió a importantes transformaciones tecnológicas y productivas. La sumatoria de tales cambios tuvo impacto sobre la estructura productiva sectorial y el esquema de representación sectorial. Para el caso específico de SRA, tales transformaciones promovieron la emergencia de nuevas problemáticas en espacios donde la entidad no poseía su mayor capacidad representativa. Así, la expansión de la soja le generó nuevas demandas a una entidad históricamente asociada a los intereses ganaderos; el crecimiento del peso productivo de la región centro-norte del país, en contraposición a una disminución del peso del centro sur (Buenos Aires, La Pampa), interpeló a SRA, que poseía su mayor despliegue representativo en esta última zona. Finalmente, cierta renovación en la composición de la cúpula agropecuaria a partir del ingreso de nuevos miembros (algunos extrasectoriales, otros sin larga historia en el sector) abrió interrogantes en una entidad que estaba más identificada con productores de larga trayectoria en la actividad y la cúpula sectorial.

En este marco se inscriben los interrogantes que guían este artículo. ¿Cómo enfrentó la SRA los cambios tecnológico-productivos, económicos y político-institucionales que afectaron al agro argentino en las últimas décadas? ¿Qué sucedió con la SRA en su rol de representante de los intereses de la cúpula del agro?

A modo de hipótesis, se sostiene que, en el período analizado, SRA se caracterizó por mantener un alto grado de inercia institucional. Esta se expresó, por un lado, en escasos cambios a nivel institucional, tanto en su esquema organizacional como en su elenco dirigente. Por otro, en el mantenimiento de los lineamientos históricos en su accionar y en sus demandas. Esta estrategia le permitió a la entidad permanecer en el escenario representativo de la cúpula, principalmente como la expresión de los actores que históricamente representó y que continuaron siendo parte de ella (ganaderos, bonaerenses y de larga trayectoria). No obstante, le acarreó una pérdida de centralidad representativa, en relación con la que tuvo desde sus inicios, debido a que los miembros ingresados a la cúpula con posterioridad a los cambios de fines del siglo XX no encontraron en SRA el canal para sus demandas. 
El artículo se organiza en cuatro apartados. En el primero de ellos, se detallan algunos aspectos teóricometodológicos relacionados con la delimitación del objeto de estudio y el actor analizado. Seguidamente, se abordan los cambios económicos y políticos, y los productivo-tecnológicos del agro, que ocurrieron en las últimas décadas del siglo XX. A continuación, se analiza cómo la SRA enfrentó dichos cambios y cómo ello afectó su representatividad. Por último, se harán algunas consideraciones finales y se dejarán planteados algunos interrogantes que pueden estimular próximas investigaciones que permitan enriquecer este campo de estudios.

\section{Aspectos TEÓRICO-METODOLÓGICOS}

Etimológicamente, representar es "hacer presente" en un determinado lugar algo que, efectivamente, no está presente (Pitkin, 1985). En el caso de la representación sectorial, se "hacen presentes" intereses y demandas de algún/os sector/es socioeconómico/s ante el Estado. Esta actividad supone la articulación de tres instancias: i) una base social, conformada por individuos y grupos con múltiples intereses; ii) una entidad representativa, que procesa dichos intereses y los erige en demandas colectivo-sectoriales; iii) el Estado, destinatario de dichas demandas.

Para captar la complejidad de esta problemática, se apeló a un marco analítico que integra las tres dimensiones. En primer lugar, una mirada "desde abajo" o estructural-económica, que permita dar cuenta de las características socioeconómicas del sector abordado. Se asume que la posición que se ocupe en dicha estructura informa el contenido de los intereses individuales y, dadas similares características socioeconómicas, se crean puntos en común para el surgimiento de intereses coincidentes. Segundo, una mirada "desde arriba" o institucional-estatal, que aborde las características que posee el destinatario de las acciones políticas (estructura, organización, reglas de funcionamiento, etc.), así como lo concerniente al tipo de intervención gubernamental (medidas y políticas públicas que implementa). Ambos aspectos de lo estatal definen el alcance de los conflictos que puedan suscitarse, el tipo de demandas que se realizan, el universo de actores intervinientes y sus posibilidades de acción.

Ahora bien, las dimensiones estructural-económica e institucional-estatal conforman el marco que delimita la estructura de opciones dentro de la cual se lleva a cabo el accionar político, pero no determinan las estrategias o movimientos específicos de los actores (Acuña, 1995b). Para desentrañar estos últimos, se requiere de una mirada "desde adentro" u organizacional-institucional, que aborde las características y el accionar de un actor político, quien por un lado es el encargado de transformar la multiplicidad de preferencias individuales en demandas colectivas y, por el otro, de "colocar con continuidad esas preferencias dentro del campo de atención de quienes ocupen las más altas posiciones en el gobierno nacional (ya sea para actuar de conformidad con ellas, para denegarlas o para reprimirlas)" (O'Donnell, 1972, p. 42). En este trabajo, este actor es una entidad representativa: la SRA.

En concordancia con estas herramientas conceptuales, se apeló a una estrategia metodológica que permitiera abordar las tres dimensiones aludidas. Para conocer la estructura económica sectorial, se tomaron datos cuantitativos ${ }^{3}$ acerca de: i) volumen de producción de los cultivos más importantes; ii) cantidad de cabezas de ganado; iii) distribución regional de las diferentes producciones.

Dentro de dicha estructura socioeconómica, interesa en particular la cúpula sectorial. En términos generales, se considera parte de ella a aquellos que poseen o controlan las mayores extensiones de tierra en las zonas de mayor valor, quienes generalmente obtienen los mayores volúmenes de producción en aquellas actividades agropecuarias más rentables, lo que los convierte en los más poderosos sectorialmente. No existe en la literatura un criterio uniforme para determinar quiénes son los integrantes de la cúpula. ${ }^{4}$ Aquí, en consonancia con Murmis y Murmis (2011), se decidió considerar como integrantes de la cúpula a quienes destinaran a la producción 10.000 o más hectáreas. Para construirla, la información se obtuvo de dos fuentes: a) el formulario C1116A confeccionado por la Oficina Nacional de Control Comercial Agropecuario 
(ONCCA), la Administración Federal de Ingresos Públicos (AFIP) y la Secretaría de Transporte de la Nación, sobre liquidación primaria de granos, correspondientes a las ventas de soja (marzo-mayo de 2009) y de trigo (octubre 2009-marzo 2010) ${ }^{5}$; b) la base de existencias ganaderas de 2013 que elabora SENASA. ${ }^{6}$ Las primeras permitieron estimar el volumen de producción de granos obtenido por cada productor y/o empresa y la segunda, la cantidad de ganado de cada firma. Posteriormente, se tradujeron ambos valores a una unidad comparable: cantidad de hectáreas. ${ }^{7}$ Esta información arrojó que integran la cúpula un total de 256 firmas. ${ }^{8}$

En relación con la instancia representativa, se optó por un estudio de caso, eligiéndose la entidad sectorial más antigua: SRA. De ella, se abordaron dos aspectos: a) su conformación institucional (estructura organizativa y elencos dirigentes); b) el accionar de la entidad, entendiendo como tal a aquellas actividades llevadas a cabo tendientes a incidir sobre las decisiones del poder político (funcionarios de gobierno, legisladores, miembros de partidos políticos, etc.) o sobre otros actores sociales. Respecto a lo primero, la información se obtuvo de documentos institucionales de la entidad (Suplementos de la revista Anales ," publicaciones especiales de SRA y su Estatuto). El accionar de SRA entre 1996 y 2008 fue obtenido del análisis del citado material institucional y de información del diario La Nación entre 1997 y 2008 . En ambos puntos se incluyó información derivada de entrevistas a dirigentes y socios de la entidad, y a informantes clave. ${ }^{10}$ Acerca de la mirada "desde arriba", en este trabajo dicho análisis se limitará a describir las políticas implementadas por los gobiernos en el período 1996-2008. Para ello se recurrirá a materiales de investigación que hayan abordado el tema.

\section{El SECTOR AGROPECUARIO. CAMBIOS ECONÓMicos, Políticos Y PRODUCTIVOS}

Las características geográficas y productivas de Argentina, el modo como se incorporó el país a la división internacional del trabajo hacia fines del siglo XIX y las relaciones de poder que se fueron configurando a lo largo del tiempo otorgan al sector agropecuario una gravitación singular en la economía nacional. Este produce la mayoría de los alimentos que consume la población, genera buena parte de las divisas extranjeras que ingresan al fisco, es un importante contribuyente a las arcas del Estado y moviliza otro conjunto de actividades económicas (servicios, agroindustria, comercios, etc.), que tienen impacto en el mercado laboral.

En las últimas décadas del siglo XIX, se produjo una gran expansión del territorio controlado por el Estado nacional, que despojó de sus tierras a sus ocupantes originarios. Su distribución fue en grandes extensiones, lo que generó la conformación de una cúpula sectorial de "no más de 300 familias propietarias que acapararon extensiones superiores a las 100.000 ha ubicadas en las mejores zonas de la región" (Pucciarelli y Castellani, 1998, p. 39), muy poderosa económicamente. De un grupo de miembros de dicha cúpula nació, hacia 1866, la entidad representativa de sus intereses, la SRA, ligada desde sus comienzos a la defensa de estos grandes propietarios, dedicados principalmente a la ganadería, actividad más relevante por entonces, y situados mayormente en torno a la provincia de Buenos Aires.

Durante el transcurso del siglo XX, aparecieron nuevas entidades representativas de distintos sectores agropecuarios que le disputaron a SRA algo de representatividad y legitimidad. Así, en1912 surgió la Federación Agraria Argentina (FAA), en representación de arrendatarios y pequeños productores pampeanos (ver Lissin, 2010). En 1932 nació la Confederación de Asociaciones Rurales de Buenos Aires y La Pampa (CARBAP), debido a una disputa entre distintas fracciones de ganaderos (ver Murmis y Portantiero, 2004; Smith, 1986) y, en la década de los 50, la Confederación Intercooperativa Agropecuaria (CONINAGRO) en representación de los intereses cooperativos. No obstante, la asociación e identificación entre los más grandes terratenientes bonaerenses y ganaderos con la SRA se mantuvo prácticamente inalterada.

Este escenario comenzó a modificarse hacia fines del siglo XX, a partir de las transformaciones económicas productivo-tecnológicas y político-institucionales ocurridas en Argentina, las que afectaron a dos de 
las dimensiones analíticas señaladas en el apartado teórico-metodológico: la estructural-económica y la institucional-estatal.

En lo que respecta a esta última, por un lado, en los años 90 se eliminaron o privatizaron buena parte de las instancias que, desde la década del 30, habían regulado el funcionamiento de la actividad agropecuaria: Junta Nacional de Granos, Junta Nacional de Carnes, Mercado de Hacienda de Liniers, Dirección Nacional de Azúcar, Mercado Consignatario Nacional de Yerba Mate, Comisión Reguladora de la Producción y Comercio de Yerba Mate, Instituto Forestal Nacional, etc. (Barsky y Gelman, 2005; Lattuada, 2006). Por el otro, los parámetros de política macroeconómica se vieron alterados, pues se asistió a un proceso de apertura comercial y financiera, a partir de la eliminación de las retenciones a las exportaciones, la desregulación del mercado de capitales y la reducción de los aranceles a la importación de productos extranjeros. En paralelo, se implantó un régimen monetario, conocido como Plan de Convertibilidad, que estableció por ley un tipo de cambio fijo de 1 a 1 entre el dólar estadounidense y el peso argentino, a la par que restringió la circulación monetaria en pesos al equivalente del monto de las reservas internacionales. Este conjunto de medidas condujo a una mayor internacionalización de la economía argentina, a la expansión de la lógica mercantil como reguladora de las relaciones económicas y a un debilitamiento de las potestades interventoras del Estado. Por otra parte, la sobrevaluación del peso sumada a la apertura comercial favoreció la importación de moderna tecnología, accesible a menores costos (para más detalles, Acuña, 1995a; Acuña y Smith, 1996; Gerchunoff y Torre, 1996; Basualdo, 2006; Lattuada, 2006; Lattuada y Nogueira, 2011, Etchemendy, 2015).

En consonancia con estos cambios, el sector agropecuario fue escenario de un fuerte proceso de innovación tecnológica, con la incorporación de avances provenientes de la biogenética, la química, la electrónica, la comunicación satelital, etc., principalmente en la agricultura. El hecho más importante lo constituyó la liberación comercial de las semillas transgénicas, en marzo de 1996. Una nueva variedad de soja (conocida como RR) se convirtió en el núcleo articulador de una serie de técnicas productivas preexistentes, empleadas aisladamente hasta ese momento (fertilizantes, siembra directa, herbicidas), que conformaron el llamado "paquete tecnológico" (Teubal y Rodríguez, 2001; Bisang, 2007a, 2007b; Anlló, Bisang y Campi, 2008; Barsky y Gelman, 2005; Lodola, 2008; etc.)

Como consecuencia de dichas transformaciones, en primer lugar, se verificó un incremento de los volúmenes de producción, especialmente el rubro agrícola, en el que se pasó de producir poco más de 50 millones de toneladas (tn) en 1996-97 a algo más de 90 millones en 2007-08. El cultivo de soja fue el principal aportante, con el 82 \% de dicho crecimiento. La ganadería, en tanto, siguió la tendencia general de la actividad en los últimos 40 años, con un stock que osciló en torno a los 50 millones de cabezas, alternando subas y bajas de dicho stock (Arceo, 2010) (Ver Figura 1). 
FIGURA 1

Producción total Cereales, Oleaginosas, Bovinos, Leche (1996-2008) (En toneladas, número de cabezas y miles de litros)

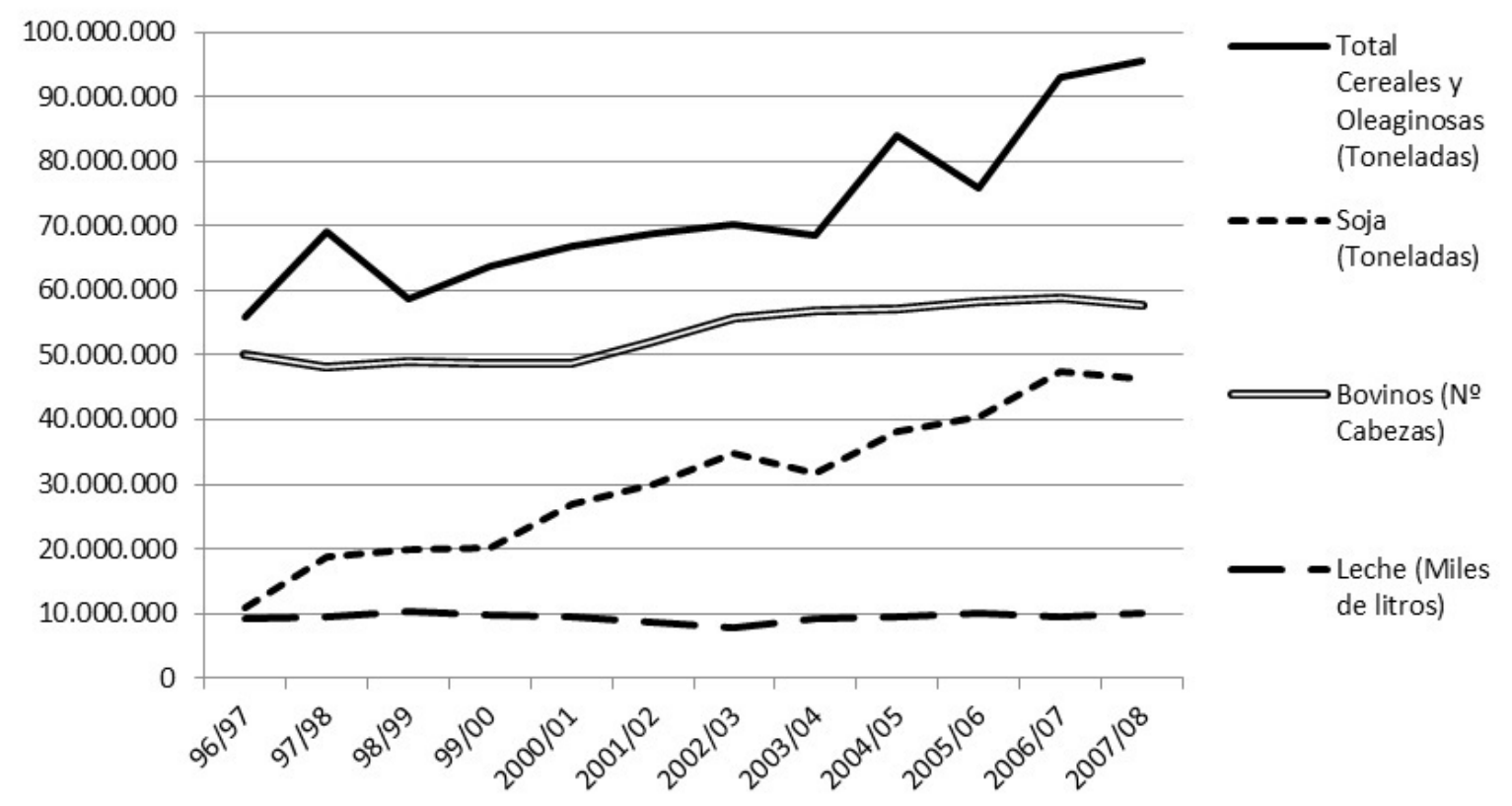

Elaboración propia sobre la base de datos Ministerio de Agricultura, Ganadería y Pesca (MAGyP)

En segundo lugar, se modificó la composición de la "canasta" de productos agrícolas, perdiendo preeminencia los cultivos tradicionales (maíz, trigo, sorgo, girasol) a favor de un marcado crecimiento de la soja, particularmente en su variante transgénica, que rápidamente desplazó a la convencional ${ }^{11}$ (Figura 2).

FIGURA 2

Participación de cultivos en el total producido (en porcentaje)

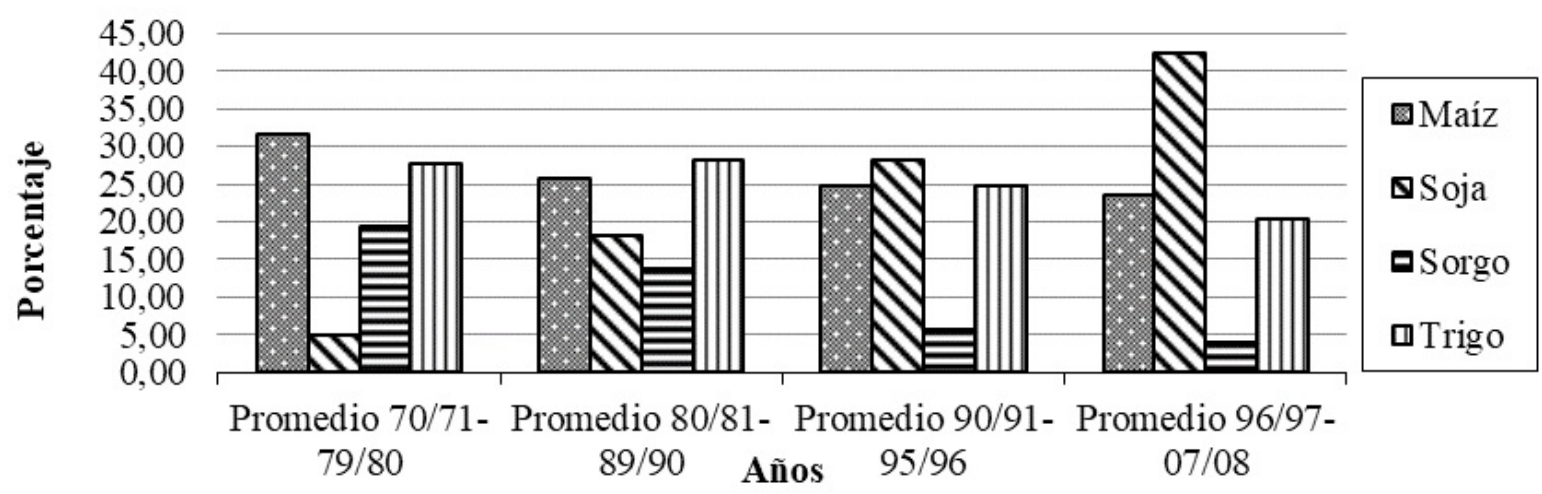

Elaboración propia sobre la base de datos de MAGyP

En tercer término, el mayor crecimiento relativo de la producción agrícola dentro de la región pampeana implicó la ampliación de su ocupación territorial. Al mismo tiempo, la ganadería sufrió un doble proceso de corrimiento: desde zonas centrales hacia el litoral y norte del país ${ }^{12}$ y, dentro de la zona central, hacia las tierras de menor aptitud y valuación económica. ${ }^{13}$ 
Por otra parte, se modificó el aporte relativo de cada región al total producido. En la producción agrícola, declinó la incidencia relativa del territorio bonaerense y de La Pampa, y crecieron las provincias ubicadas del centro hacia el norte del país (Córdoba, Santa Fe, Santiago del Estero, Chaco y Salta) (Figura 3).

FIGURA 3

Agricultura, diferencia de aporte por provincia 2007/08-1996/97 (en \%)

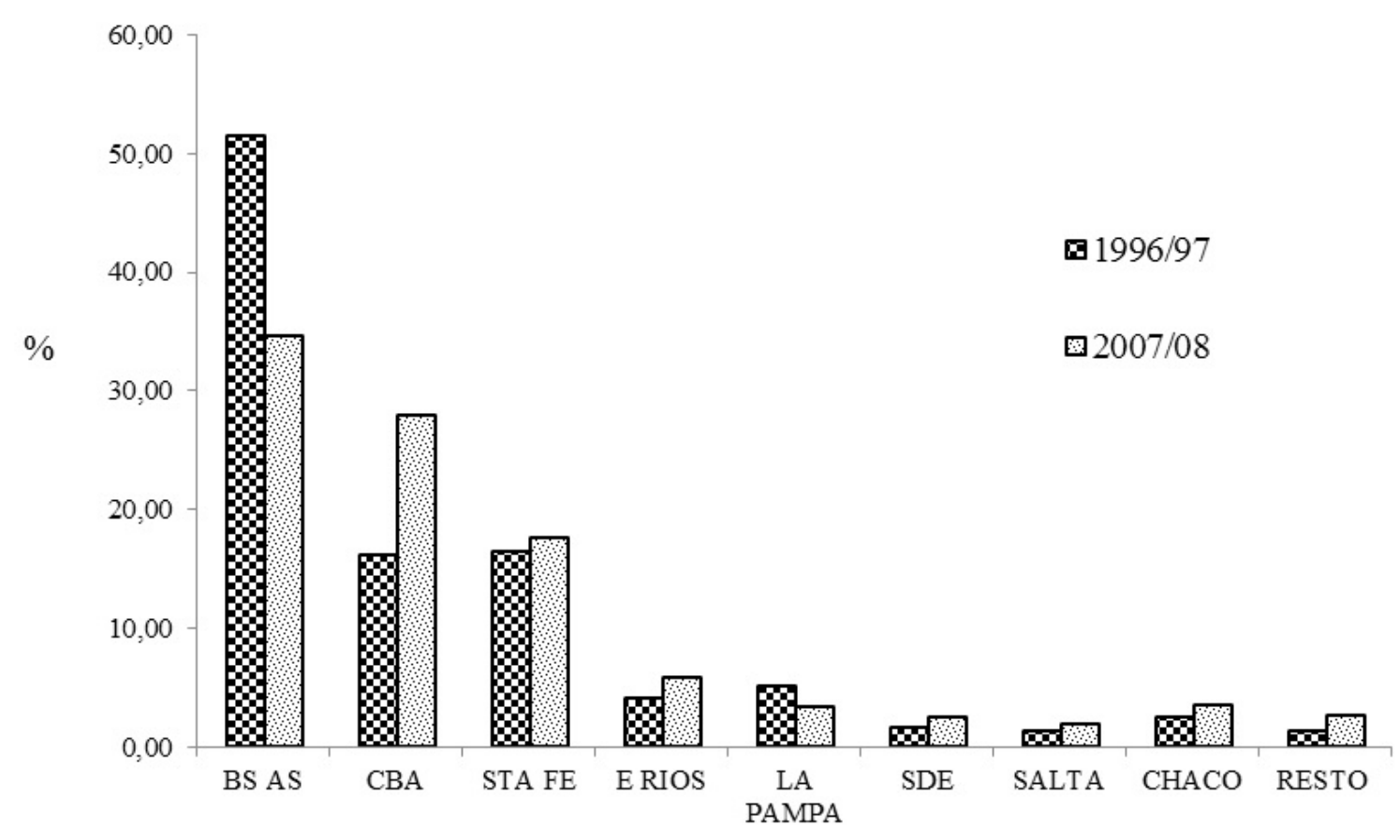

Elaboración propia sobre la base de datos de MAGyP

\section{TrANSFORMACIONES EN LA CÚPULA Y ELENCO REPRESENTATIVO}

Los cambios ocurridos también tuvieron impacto en la conformación y en las características de la cúpula agropecuaria. Para su caracterización se tomaron en cuenta tres variables: i) el tipo de actividad agropecuaria desarrollado, ii) la ubicación geográfica de las explotaciones y sedes administrativas, y iii) su antigüedad en la actividad.

Para el tipo de actividad agropecuaria, se clasificó entre firmas Exclusivamente Ganaderas (EG) (aquellas dedicadas totalmente a la ganadería o cuya producción agrícola representa menos del $20 \%$ del total de su producción, medido en número de hectáreas); Exclusivamente Agrícolas (EA) (la producción agrícola representa la totalidad de su producción o la producción ganadera explica un porcentaje menor del $20 \%$ del total, medido en número de hectáreas); Mixtas (cuya producción se compone casi igualitariamente de ambos rubros). De acuerdo con los datos obtenidos, dos tercios de las firmas que integran la cúpula del agro argentino son Exclusivamente Ganaderas, un 22 \% son Exclusivamente Agrícolas y solo el 11 \% son Mixtas 14 (ver Tabla 1).

En cuanto a la ubicación geográfica, aproximadamente un tercio de las firmas de la cúpula tiene explotaciones en tres o más provincias argentinas (Nacionales), en tanto los restantes dos tercios se sitúan sólo en una o dos (Regional/Provinciales). El predominio lo ostenta la provincia de Buenos Aires, donde el $45 \%$ de los miembros de la cúpula tiene, al menos, una explotación agropecuaria. Entre quienes tienen 
un alcance Nacional, un $60 \%$ posee alguna de sus explotaciones en territorio bonaerense y poco menos del $40 \%$ fuera de éste, en tanto entre las firmas Regional/Provinciales la relación es la inversa. Acerca del lugar donde se ubica la sede central, casi un 45 \% la posee en la Ciudad de Buenos Aires (Capitalinos), un $6 \%$ en la provincia de Buenos Aires (Bonaerenses) y el restante $47 \%$ está situado en el resto de las provincias del país (Federales) (sobre el 1\% restante, se carece de datos).

TABLA 1

Distribución de las firmas de la cúpula según tipo de actividad agropecuaria

\begin{tabular}{|l|l|l|}
\hline Tipo de actividad agropecuaria & Cantidad & \% \\
\hline Ganadería exclusivamente & 169 & 66,02 \\
\hline Agricultura exclusivamente & 58 & 22,66 \\
\hline Mixta & 29 & 11,33 \\
\hline Total & 256 & 100,00 \\
\hline
\end{tabular}

Elaboración propia a partir de Base de Existencias Ganaderas 2013; Formulario C1116A de ONCCA -AFIP-

Secretaría de Transporte, Trigo (período octubre 2009-marzo 2010) y Soja (período marzo-mayo de 2009)

Si se vincula el lugar donde la firma posee la sede central con el tipo de actividad agropecuaria que desarrolla, puede verse que quienes son exclusivamente ganaderos y mixtos poseen la mayor parte de sus sedes en CABA. Contrariamente, tres cuartas partes de los exclusivamente agrícolas tienen sede en provincias que no son Buenos Aires y sólo un $13 \%$ tiene sede capitalina (ver Tabla 2).

TABLA 2

Ubicación geográfica de la sede central según tipo de actividad agropecuaria (en cantidad de casos y porcentajes)

\begin{tabular}{|l|l|l|l|l|l|l|}
\hline \multirow{2}{*}{$\begin{array}{l}\text { Sede } \\
\text { central }\end{array}$} & \multicolumn{5}{|c|}{ Tipo de actividad agropecuaria } \\
\hline & Agricola & $\%$ & Ganadero & $\%$ & Mixto & $\%$ \\
\hline Capitalino & 8 & 13,79 & 88 & 52,07 & 19 & 65,52 \\
\hline Bonaerense & 7 & 12,07 & 7 & 4,14 & 3 & 10,34 \\
\hline Federal & 42 & 72,41 & 73 & 43,20 & 7 & 24,14 \\
\hline Sin datos & 1 & 1,72 & 1 & 0,59 & & 0,00 \\
\hline \hline Total & 58 & 100,00 & 169 & 100,00 & 29 & 100,00 \\
\hline \hline
\end{tabular}

Elaboración propia a partir de Base de Existencias Ganaderas 2013; Formulario C1116A de ONCCA -AFIPSecretaría de Transporte, Trigo (período octubre 2009-marzo 2010) y Soja (período marzo-mayo de 2009)

Para determinar la antigüedad, se tomó el año de creación de la firma, según su formato societal actual. Las fuentes de información fueron las páginas de las propias empresas y los sitios online data cuit y trade nosis. De acuerdo con estos datos, el $8 \%$ de las empresas que integran la cúpula fueron creadas antes de 1950, un $18 \%$ entre 1950 y 1970, un $30 \%$ en el período $1970-1990$ y un $43 \%$ se constituyeron luego de 1990 . En relación con este último dato, pudo haber ocurrido una modificación en el formato societal de una empresa 
ya existente, o tratarse de una empresa de reciente creación por el ingreso de capitales sin presencia anterior en el sector (las fuentes de información de donde se obtuvieron los datos no permiten diferenciar entre una y otra). Más allá de esto, el hecho de que más de un $40 \%$ de las firmas que integran la cúpula hayan tomado su formato societal actual luego de 1990, da indicios para pensar que, hacia finales del siglo XX, la cúpula del agro argentino asistió a un proceso de renovación (ver Tabla 3 ).

Si se correlaciona el año de creación de la firma con el tipo de actividad agropecuaria que desarrolla, se observa que las firmas ligadas a la producción ganadera son las más antiguas. Contrariamente, el $51 \%$ de las puramente agrícolas se crearon con posterioridad a 1990.

TABLA 3

Año de inicio de actividades

\begin{tabular}{|l|l|l|}
\hline Categoría & Cantidad & $\%$ \\
\hline Antes 1950 & 15 & 7,98 \\
\hline \hline $1950-1970$ & 35 & 18,62 \\
\hline \hline $1970-1990$ & 57 & 30,32 \\
\hline 1990 en adelante & 81 & 43,08 \\
\hline \hline Subtotal & 188 & 100,00 \\
\hline Sin datos & 68 & \\
\hline \hline Total & 256 & \\
\hline \hline
\end{tabular}

Elaboración propia sobre la base de las páginas de internet de las empresas, y sitio de internet data cuit y trade nosis online.

Estos datos indican que el proceso de renovación de la cúpula ha sido más fuerte en la agricultura, lo cual hace suponer que quienes ingresaron a la cúpula lo hicieron desarrollando principalmente esta actividad (ver Tabla 4).

TABLA 4

Año de creación de la empresa según tipo de actividad agropecuaria (En cantidad de empresas y porcentaje)

\begin{tabular}{|l|l|l|l|l|l|l|}
\hline Categoría & Agrícola & $\%$ & Ganadero & $\%$ & Mixto & $\%$ \\
\hline Antes 1950 & 1 & 3,45 & 13 & 9,77 & 1 & 3,85 \\
\hline \hline $1950-1970$ & 2 & 6,90 & 24 & 18,05 & 9 & 34,62 \\
\hline $1970-1990$ & 11 & 37,93 & 41 & 30,83 & 5 & 19,23 \\
\hline $\begin{array}{l}1990 \text { en } \\
\text { adelante }\end{array}$ & 15 & 51,72 & 55 & 41,35 & 11 & 42,31 \\
\hline \hline Subtotal & 29 & 100,00 & 133 & 100,00 & 26 & 100,00 \\
\hline \hline SD & 29 & & 36 & & 3 & \\
\hline \hline Total & 58 & & 169 & & 29 & \\
\hline \hline
\end{tabular}


Elaboración propia a partir de Base de Existencias Ganaderas 2013; Formulario C1116A de ONCCA AFIP-Secretaría de Transporte, Trigo (período octubre 2009-marzo 2010) y Soja (período marzomayo de 2009); páginas de internet de las empresas y sitios de internet cuit online, data cuit y trade nosis

Si se relaciona el lugar donde la empresa posee la sede con el año de inicio de actividades, se observa que con antigüedad anterior a 1950 sólo hay firmas con sede en CABA y en provincia de Buenos Aires. Por el contrario, sólo un $30 \%$ de las firmas capitalinas fueron creadas luego de 1990, número comparativamente menor al $41 \%$ de las Bonaerenses y al $60 \%$ de las Federales (ver Tabla 5).

TABLA 5

Año inicio de actividades según sede central (En cantidad de empresas y porcentaje)

\begin{tabular}{|l|l|l|l|l|l|l|}
\hline Categoria & Capitalino & $\%$ & Bonaerense & $\%$ & Federal & $\%$ \\
\hline Antes 1950 & 14 & 14,29 & 1 & 8,33 & & \\
\hline $1950-1970$ & 23 & 23,47 & 2 & 16,67 & 9 & 11,84 \\
\hline $1970-1990$ & 31 & 31,63 & 5 & 41,67 & 21 & 27,63 \\
\hline $\begin{array}{l}1990 \text { en } \\
\text { adelante }\end{array}$ & 30 & 30,61 & 5 & 41,67 & 46 & 60,53 \\
\hline Subtotal & 98 & 100,00 & 12 & 100,00 & 76 & 100,00 \\
\hline Sin datos & 17 & & 4 & & 46 & \\
\hline Total & 115 & & 16 & & 122 & \\
\hline \hline
\end{tabular}

Elaboración propia a partir de Base de Existencias Ganaderas 2013; Formulario C1116A de ONCCA AFIP-Secretaría de Transporte, Trigo (período octubre 2009-marzo 2010) y Soja (período marzomayo de 2009); páginas de internet de las empresas y sitios de internet cuit online, data cuit y trade nosis

La actual cúpula agropecuaria está compuesta por un número de firmas cercano al 0,5\% de la totalidad de los productores, exhiben un alto grado de especialización productiva ( 9 de cada 10 firmas son exclusivamente ganaderas o agrícolas) y se extienden geográficamente por 17 provincias, ${ }^{15}$ aunque predominan las asentadas en territorio bonaerense. Se observa que en las últimas décadas la cúpula sectorial ha verificado un proceso de renovación, ya que algo más del 40 \% de las empresas que la conforman inició sus actividades luego de 1990. Este proceso fue más marcado en la agricultura que en la ganadería, probablemente en consonancia con la expansión de la producción de soja. Asimismo, tuvo más impulso fuera del territorio bonaerense que dentro de éste. Dado que en la provincia de Buenos Aires se ubican las firmas de mayor antigüedad, puede pensarse también que en la renovación de la cúpula tuvieron mayor peso empresas noveles en el sector.

En síntesis, los cambios económicos, políticos y productivo-tecnológicos sucedidos en Argentina desde las últimas décadas del siglo XX generaron un nuevo escenario socioproductivo. Si, como fue señalado en el marco conceptual, de las características que este escenario posea pueden inferirse los intereses de los miembros del sector, dichos cambios generaron el marco para la emergencia de nuevos intereses. Para el caso específico de la entidad estudiada en este trabajo, SRA, surgieron en ámbitos donde ésta no tenía su mayor expertise representativa: los intereses ligados al crecimiento del cultivo de soja (la SRA históricamente estuvo asociada a la defensa de intereses ganaderos), el mayor crecimiento de la región centro-norte del país, en desmedro de la centro-sur (Buenos Aires, La Pampa), donde SRA siempre tuvo su mayor capacidad representativa, y, finalmente, los cambios en la composición de la cúpula se dieron a partir del ingreso de nuevos miembros, muchos de ellos sin trayectoria en el sector ni situados en el ámbito capitalino-bonaerense, donde SRA tenía más influencia. Estos cambios implicaron un desafío para la actividad representativa de SRA, tema que será abordado a continuación. 


\section{LA SRA FRENTE AL NUEVO ESCENARIO}

El análisis realizado sobre las dimensiones estructural-económica e institucional-estatal da el marco de opciones que los actores enfrentan, pero no permite conocer "las estrategias o movimientos específicos" de los mismos. Para ello, la mirada “desde adentro" abordará la entidad representativa SRA.

Retomando las preguntas del artículo, ¿cómo enfrentó SRA los cambios económicos, políticos y productivo-tecnológicos acontecidos en las últimas décadas? ¿Qué implicancias tuvo dicho comportamiento respecto de su rol de representante de los intereses de la cúpula del agro? La hipótesis enunciada señala que SRA, durante el período 1996-2008, exhibió un alto grado de inercia institucional, lo que implicó el mantenimiento de sus pautas de comportamiento, intrainstitucionales y públicas, habituales; el reforzamiento de la vinculación con su base social histórica (propietarios de la tierra, principalmente bonaerenses, ganaderos y con larga trayectoria en el sector); y la no recepción, o recepción tardía, de las nuevas problemáticas emergentes de los cambios ocurridos, particularmente lo relativo al cultivo de soja. Esto tuvo como consecuencia una pérdida de su centralidad representativa, a la vez que el mantenimiento de la representación de su base social tradicional.

Como modo de constatación de la inercia institucional de SRA, se analizaron tres aspectos: i) la configuración de la estructura de gobierno de SRA, ii) la composición del elenco dirigencial y iii) el accionar de la entidad entre 1996 y 2008.

\section{Estructura DE GOBIERNo DE SRA}

El Estatuto Social de SRA ${ }^{16}$ (ES) consagra una estructura de gobierno compuesta por diversas instancias, donde la máxima autoridad es la Asamblea General Ordinaria de Socios. Ésta elige a los integrantes de la Comisión Directiva (CD), ${ }^{17}$ órgano principal de toma de decisiones, la cual nombra, a su vez, a la Mesa Directiva (MD) ${ }^{18}$ como órgano ejecutivo. Se completa dicho organigrama con un Consejo Institucional (CI), conformado por las "entidades representativas de sectores específicos de la producción agropecuaria, la agroindustria, el comercio, y demás servicios y actividades de índole técnica, científica, profesional u otra, relacionados con el campo" (Artículo $47 \mathrm{ES}$ ) y un Consejo Federal (CF) "integrado por Asociaciones o Sociedades Rurales representativas de productores agropecuarios asentados en zonas geográficas o jurisdicciones determinadas" (Artículo $47 \mathrm{ES}$ ).

El detalle de los cargos unipersonales (presidente, vicepresidentes, secretarios, directores de áreas, etc.), así como el de los vocales, aportan poca información haciendo abstracción de las características de sus dirigentes. Resulta de mayor utilidad analizar la composición de aquellas instancias de su estructura organizacional en las que puedan entreverse los intereses que expresa, ya sean productivos o regionales. Tal es el caso de la estructura territorial, así como el de la distribución de los Vocales Titulares por Distrito (VGD) y los delegados zonales, el Consejo Institucional y el Consejo Federal.

La estructura territorial de SRA está dividida en 14 distritos. Cinco (35\%) se encuentran en la zona central ( 3 en Buenos Aires, 1 en Córdoba y 1 para Santa Fe), tres ( $21 \%)$ en el litoral ( 1 en Entre Ríos, 1 para Corrientes y Misiones y 1 para Chaco y Formosa) y el resto en las zonas Sur, Noroeste y cuyana. Esta distribución implica una mayor presencia de la entidad en dichas regiones, además de un número más alto de exponentes de ellas en la Comisión Directiva. Ambos aspectos hacen suponer que los intereses productivos de tales zonas están más presentes en las preocupaciones y en el accionar de SRA. A su vez, en distintas ciudades de cada uno de estos distritos hay delegaciones, coordinadas por el Vocal de distrito. En 2010, la SRA contaba con 302 delegados, de los cuales el 31,5\% vivía en la Ciudad de Buenos Aires o localidades que la circundan, el $23 \%$ en provincia de Buenos Aires y el 45,5\% lo hacía en el resto del país. ${ }^{19}$ El lugar de residencia de 
los delegados muestra un mayor peso de la ciudad y la provincia de Buenos Aires en la estructura de SRA, reforzando la preeminencia de los intereses vinculados a la zona central y bonaerense-capitalina del país.

Por su parte, el Consejo Institucional está compuesto por 63 entidades, de las cuales el $65 \%$ corresponde al rubro ganadería. El resto se distribuye entre asociaciones de diversas producciones (fruticultura, olivicultura, yerba mate, apicultura, tabaco, arroz, etc.) En términos de su localización geográfica, el $71 \%$ de estas entidades tienen su sede en la Ciudad de Buenos Aires, el $14 \%$ en la provincia de Bs. As. y sólo el $15 \%$ restante se ubica en el resto del país.

El Consejo Federal se integraba, hacia el año 2010, por 115 Sociedades Rurales de distintos puntos del país. Entre ellas, 33 se encontraban situadas en la provincia de Buenos Aires (28 \%), siendo con bastante diferencia la de mayor presencia. Le sigue en importancia la región litoral (Corrientes, Entre Ríos, Formosa y Misiones) con un $23 \%$. Si a éstas se les suman las 13 de Chaco (11,3\%), se observa que entre provincia de Buenos Aires y el Noreste argentino (NE) sumaban casi dos tercios del total de entidades adheridas a SRA. El tercio restante se ubicaba en las otras provincias argentinas.

La conformación del organigrama de cualquier institución no responde a un diseño estándar ni constituye algo neutro en relación con los intereses presentes en su interior. Por el contrario, es el reflejo de los intereses, tensiones y relaciones de poder existentes en su seno. En este sentido, la información extraída acerca de la estructura de gobierno de SRA muestra una constitución que hacen presente mayormente intereses ligados a la producción ganadera, principalmente bovina y ovina, lo que se ve reflejado en la conformación del CI. Asimismo, el detalle de la composición del CF, de la estructura de distritos y de la residencia de los delegados zonales de SRA hace más fuertemente presentes los intereses y problemáticas situados geográficamente en la provincia de Buenos Aires y la región noreste del país. Esto refuerza la presencia de intereses ganaderos en SRA, ya que, además de la importante presencia bonaerense, se encuentra bien representada la región litoralnoreste, hacia donde se desplazó la ganadería como consecuencia de la expansión agrícola verificada desde la década del 90 en la zona central del país.

\section{Elenco DiRigente de SRA. COMPOSICIÓN Y CARACTERÍSTICAS}

La inclusión de este punto obedece a la premisa de que habrá mayor comunidad de intereses entre socios y dirigentes que tengan similares características socio-económicas y/o productivas y, por ello, mayor disposición de estos últimos a hacer presentes los intereses ligados a su propia actividad. Para su abordaje, se elaboró un listado de dirigentes con todos los que fueron parte, al menos en una ocasión, de la CD y/ o de la MD, en calidad de titulares, entre el ejercicio 1995-96 y el 2007-08. Para determinar su tiempo de permanencia, se contó el período, continuo o interrumpido, en el que la persona tuvo participación en algún órgano de conducción de la entidad, ya sea en calidad de titular o de suplente.

Durante la etapa 1996-2008, 68 personas integraron la CD y/o la MD de SRA, observándose una alta permanencia en los cargos directivos, dado que casi un $60 \%$ de los dirigentes permanecieron al menos 10 años en algún cargo de la CD o la MD y un $26 \%$ lo hizo entre 5 y 10 años (Panero, 2017). En cuanto a la actividad económica que desempeñaron los dirigentes de SRA del período 1996-2008, un 64 \% tuvo como actividad principal la ganadería. Una fracción menor (9\%) se dedicó principalmente a la agricultura u otras actividades relacionadas con el agro, y otro $12 \%$ no registró actividad productiva primaria en el sector y ejerció otra ocupación (consignatarios de hacienda, empresarios inmobiliarios, veterinarios, abogados, profesores universitarios, funcionarios públicos). Asimismo, una porción del elenco dirigencial, además de las tareas agropecuarias, poseía intereses en otro tipo de actividad (empresarios vitivinícolas, empresarios de medios, industriales del rubro agroalimentos, etc.). ${ }^{20}$ (Panero, 2017)

Este perfil productivo más ligado a lo ganadero de los dirigentes de SRA se profundizó a lo largo del período considerado. Del conjunto de personas que condujeron la entidad entre 1996 y 2008, el $53 \%$ de quienes ingresaron antes de 1990 se dedicaba a la ganadería. De los que se incorporaron entre 1990 y 2000, el $62 \%$ 
era ganadero, en tanto de los que se sumaron con posterioridad a 2000 el $73 \%$ tuvo como actividad principal la ganadería (ver Tabla 6).

TABLA 6

Perfil productivo dirigentes SRA (Cantidad de miembros y porcentaje)

\begin{tabular}{|l|l|l|l|}
\hline $\begin{array}{l}\text { Año ingreso a } \\
\text { SRA }\end{array}$ & $\begin{array}{l}\text { Total } \\
\text { dirigentes }\end{array}$ & $\begin{array}{l}\text { Actividad principal } \\
\text { ganadería }\end{array}$ & $\%$ \\
\hline Antes 1990 & 13 & 7 & 53,85 \\
\hline $1990-2000$ & 40 & 25 & 62,50 \\
\hline $\begin{array}{l}\text { Posterior año } \\
2000\end{array}$ & 15 & 11 & 73,33 \\
\hline
\end{tabular}

Elaboración propia sobre la base de Anales de SRA, Base de Existencias Ganaderas SENASA 2013 y formulario C1116A de ONCCA-AFIP-Secretaría de Transporte

En cuanto a la ubicación geográfica de los establecimientos ${ }^{21}$ de quienes han conformado el elenco dirigente de SRA entre 1996 y 2008, un 44\% se ubica en la provincia de Buenos Aires. El resto de los establecimientos de los dirigentes se distribuye entre provincias de la región central del país (Córdoba, Santa Fe, La Pampa), donde se sitúa aproximadamente el 20\%; el litoral (Entre Ríos, Corrientes, Formosa) con un 12\%; la zona norte del país (Tucumán, Santiago del Estero, Jujuy y Salta), que presenta el 11\%; en tanto en Cuyo se radica el 6\%, lo mismo que en el sur del país.

En suma, el elenco dirigencial de SRA tuvo un importante grado de permanencia y continuó siendo integrado mayoritariamente por productores ganaderos y bonaerenses, lo que enfatiza sus rasgos históricos. La renovación dirigencial que hubo profundizó el perfil ganadero, al tiempo que se abrió moderadamente la participación de dirigentes cuyas explotaciones se encuentran en el litoral y norte del país.

\section{El ACCIONAR DE SRA ENTRE 1996 y 200822}

Retomando lo señalado más arriba, el accionar refiere a las actividades llevadas a cabo por la entidad, tendientes a incidir sobre las decisiones del poder político o de otros actores sociales. Tal accionar permite identificar los intereses y demandas que la entidad hace presentes públicamente. ${ }^{23}$ Se consideraron: a) el contenido del accionar (qué se demanda, propone, rechaza o reivindica); b) el destinatario del accionar; c) los ejes de conflicto que se generan. En función de ello, se observaron cuatro momentos dentro de la etapa 1996-2008:

i. El primero, entre 1996 y 1999. En esta etapa la entidad acordó con el rumbo macroeconómico emprendido por el gobierno nacional de entonces (Carlos Menem era el presidente), entablando una relación de cercanía y mutuo apoyo. Esto le valió a la entidad un acceso habitual a distintos miembros del gabinete gubernamental y al presidente de la Nación. Además, en este período SRA adquirió el predio de Palermo donde habitualmente realiza su muestra anual, a un precio sospechado por su subvaluación (Muro de Nadal, 2009)

Coincidiendo con los trazos generales de una política económica que abdicó de hacer política monetaria (por efecto del plan de convertibilidad) y política comercial (debido a la liberación del comercio internacional y la anulación de las retenciones a las exportaciones), el accionar de SRA estuvo dirigido hacia aquellos ámbitos del Estado donde éste conservaba algún grado de capacidad de decisión y acción (aspectos sanitarios, laborales e impositivos principalmente). Las demandas 
estuvieron más enfocadas en temas relativos a la ganadería, especialmente la bovina, y en menor medida la ovina. Por otro lado, en esta etapa se aprobó el cultivo de soja transgénica, frente al cual la SRA no solamente no lo promovió, sino que primeramente omitió la consideración del tema y luego tomó una posición de cautela intentando desligarse de responsabilidades sobre la adopción del nuevo producto (Panero, 2013).

ii. Un segundo momento transcurrió desde fines de 1999 hasta mayo de 2003, etapa que se caracterizó por el agotamiento del modelo de convertibilidad, la crisis de 2001-2002 y la salida postdevaluación. En ese marco, las acciones de SRA estuvieron mayormente enfocadas hacia los lineamientos macroeconómicos que se imprimirían desde el Estado, ante la incertidumbre de su nueva configuración, dejando poco lugar a las temáticas estrictamente sectoriales. Previamente a la devaluación del peso, concretada en enero de 2002, los temas predominantes del accionar ruralista fueron demandas frente a la crisis de la economía argentina, la inestabilidad política y la falta de rentabilidad sectorial. El cambio de escenario a la salida de la convertibilidad, en enero de 2002, abrió tres frentes de preocupación: la incertidumbre ante la variación de los precios relativos de la economía, las deudas contraídas en dólares y la reimplantación de las retenciones a las exportaciones de algunos bienes.

iii. El tercer período se desarrolló entre mayo de 2003 y comienzos de 2006. En esta etapa, la situación comenzó a estabilizarse bajo nuevas reglas de juego. La economía retomó una senda de crecimiento con un esquema macroeconómico favorable a los bienes transables (los agropecuarios entre ellos) y la situación política logró estabilizarse luego de las elecciones presidenciales de 2003. En ese marco, la SRA manifestaba "conformidad por el comportamiento general de la economía, particularmente por el aumento en los niveles de actividad registrados y los índices récord de recaudación fiscal” (revista Anales SRA, 2004, p. 70). Esto permitió una relativa buena relación con el gobierno nacional, que se quebró a principios de 2006 con la intervención gubernamental en el mercado de carnes.

En estos años, el accionar de la entidad estuvo enfocado principalmente hacia el Estado y referido a temáticas macroeconómicas, tratando de hacer presentes los intereses del sector productivo primario en general, en primer lugar defendiendo aquellos aspectos de los lineamientos económicos que incrementaban la rentabilidad sectorial (tipo de cambio beneficioso y apertura de mercados internacionales), y oponiéndose a aquellos otros que la recortaban (mayores regulaciones estatales y retenciones). En particular, siguieron teniendo mayor peso las demandas relativas a la actividad ganadera, tanto en lo referido a la lechería como a la producción de carne. Dichas acciones se incrementaron, en cantidad e intensidad, hacia fines del período, ante los intentos del gobierno nacional por alcanzar acuerdos que regularan el precio de la carne, y más aún frente a la disposición de establecer un peso mínimo de faena para los vacunos. En paralelo al mantenimiento de su atención a las problemáticas de la ganadería, en la etapa 2003-2006 las acciones de SRA referidas a temáticas vinculadas con la producción de granos se incrementaron en comparación con las etapas anteriores. Particularmente, tuvieron que ver, por un lado, con la oposición de SRA a la implementación por parte del gobierno nacional de derechos de exportación de los productos agropecuarios. Por otro, aparecieron algunos puntos de conflicto en torno al cultivo de soja, relativos al precio del glifosato y las regalías que pretendía cobrar la empresa Monsanto por las semillas transgénicas.

iv. El último período se desarrolló entre marzo de 2006 y julio de 2008. El grueso de las demandas de SRA en estos dos años estuvo dirigido hacia el Estado y en torno a tres temas: la intervención en el mercado de carnes, la intervención en el mercado de trigo y las retenciones a las exportaciones de granos. Las relaciones con el gobierno se caracterizaron por un clima de tirantez; el punto máximo de tensión se alcanzó entre marzo y julio de 2008, al desatarse un conflicto de magnitud entre el gobierno y las entidades representativas sectoriales, nucleadas en la Mesa de Enlace de Entidades Agropecuarias. Si bien este conflicto permitió canalizar desacuerdos y enfrentamientos varios entre 
las partes, el desencadenante fue el intento del gobierno nacional de implementar retenciones móviles a la soja, trigo, maíz y girasol en un momento de fuerte alza internacional de los precios de estos productos. $^{24}$

En suma, el análisis del accionar de SRA durante el período 1996-2008 permite dar cuenta de que la entidad exhibió un importante grado de inercia institucional. En cuanto al contenido de las demandas, se mantuvo una importante atención en los temas relacionados a la ganadería, así como a los de algunas producciones granarias más tradicionales (maíz, trigo). Esto ocurrió de manera casi exclusiva hasta comienzos de los 2000, permaneciendo dichas demandas durante todo el lapso analizado. Lo que sí mostró cambios fue la aparición de un mayor número de demandas relativas a la producción de soja, las cuales estuvieron prácticamente ausentes hasta los inicios de los 2000 y recién a partir de esta fecha comenzaron a aparecer. No obstante, no fueron una prioridad para la entidad, que las hizo presentes sin titubeos cuando no afectaban la situación de otras producciones. Por el contrario, cuando entraron en conflicto con otros intereses presentes entre los socios de SRA (carne o cereales, por ejemplo), las demandas por la soja fueron presentadas dentro de planteos más generales o, en algunos casos, de manera subordinada a ellos.

Por otra parte, SRA corroboró su perfil representativo de intereses de los productores primarios, lo cual pudo observarse, más allá del contenido de sus demandas, en los ejes de conflicto que planteó. Éstos, por un lado, estuvieron centrados en las intervenciones regulatorias por parte del Estado y en su rol fiscal, en tanto ello constituía un incremento de sus costos. Otros puntos de conflicto se presentaron en relación con aquellos que podían disputarles a sus asociados parte de su rentabilidad: empresas proveedoras, contratistas, obreros rurales, industrias. En relación con estas últimas, SRA mantuvo una histórica disputa con las industrias que considera "ineficientes" o "artificiales" (aquellas que elaboran bienes no provenientes del agro). No obstante, el perfil de SRA como defensora de la producción primaria quedó más claramente expresado cuando el eje de conflicto se instaló frente a las industrias que SRA considera "naturales" (las que procesan materias primas agropecuarias: molinos harineros, frigoríficos, etc.). Con estas últimas, las disputas se plantearon en paralelo a aquellas intervenciones estatales (cupos de exportación, o prohibiciones temporarias, o retenciones a las exportaciones) que "desacoplaban" los precios locales de los internacionales y, a juicio de SRA, les otorgaban injustas ventajas a las industrias procesadoras de materias primas agropecuarias.

\section{Conclusiones}

Este artículo tuvo como objetivo hacer un aporte al campo de estudios de la representación de intereses sectoriales, abordando en particular lo ocurrido con la representación de la cúpula del sector agropecuario luego de los cambios económicos, políticos y sociales sucedidos en Argentina desde las últimas décadas del siglo XX. Específicamente, se enfocó en la discusión acerca de lo ocurrido con los actores históricotradicionales, analizando la entidad representativa sectorial más antigua y tradicional: la Sociedad Rural Argentina.

La investigación realizada permitió arribar a dos conclusiones. En primer lugar que, frente a dichos cambios, SRA exhibió un alto grado de inercia en su comportamiento. Dicha inercia se manifestó en las escasas modificaciones de su organigrama institucional, en el elevado nivel de permanencia de su dirigencia y en un accionar tendiente a seguir expresando las demandas más vinculadas a sus históricos núcleos problemáticos: los ligados a la producción ganadera, a los productores de larga trayectoria en el sector rural y preferentemente situados en la provincia de Buenos Aires.

Una segunda conclusión refiere a la situación actual de SRA en tanto representante de la cúpula del agro argentino, luego de los cambios ocurridos y las respuestas de SRA ante ellos. Se concluye que SRA ha logrado permanecer como representante de una fracción de la cúpula del agro argentino: aquellos productores que poseen larga trayectoria en el sector se dedican principalmente a la ganadería y sus explotaciones se encuentran 
preferentemente en la provincia de Buenos Aires. En los últimos años, ha ampliado en algo su representación territorial hacia la zona litoral-noreste del país, donde algunos de estos productores han desplazado algo de su ganadería, fruto del proceso de corrimiento que experimentaron. No obstante, ha perdido la exclusividad o preeminencia que tuvo durante buena parte del siglo XX, ya que aquellos productores que crecieron fuertemente a partir de los cambios de las últimas décadas del siglo anterior e ingresaron a la cúpula a partir de ese momento (principalmente como consecuencia del crecimiento agrícola), y que mayormente no poseen apellidos con tradición en el sector, no se sienten representados por SRA.

Finalmente, las conclusiones y la evidencia empírica aportadas por este trabajo abren la puerta al planteamiento de nuevos interrogantes. ¿Por qué la SRA, expresión de los más grandes productores desde su creación, tuvo dificultades en expresar los intereses de los nuevos productores que se incorporaron a la cúpula hacia fines del siglo XX? ¿Qué entidad/es asume/n el papel representativo de este nuevo estrato de productores? ¿Cuál es el papel de las entidades "técnicas" (AACREA, AAPRESID) así como de aquellas organizadas por cadena de productos (ACSOJA, MAIZAR, ARGENTRIGO) en esta nueva etapa? ¿Cuál es la relación entre estas entidades y la SRA? Estas preguntas, y otras que puedan surgir, seguramente podrán estimular investigaciones venideras que permitan continuar enriqueciendo este campo de estudios.

\section{RefERENCiAS}

Acuña, Carlos (1995a). Política y economía en la Argentina de los 90 (O por qué el futuro ya no es lo que solía ser). En La nueva matriz politica argentina. (pp. 331-383). Bs. As.: Nueva Visión.

Acuña, Carlos (1995b). The Industrial Bourgeoisie as a Political Actor: An Overall Introduction. Tesis doctoral inédita. Chicago: Universidad de Chica

Acuña, C. y Smith, W. (1996). La lógica política de liberalización económica en la administración de Menem. Desarrollo Económico, 36(141).

Anlló, G., Bisang, R. y Campi, M. (2008). Una revolución (no tan) silenciosa. Claves para repensar el agro en Argentina. Desarrollo Económico, 48 (190-191), 165-208.

Anlló, Guillermo (2013). Cambio de paradigma tecno-productivo y ¿crisis de representación? Nuevas y viejas formas entidades de representación de la actividad agrícola. En Anlló et al. (Ed). Claves para repensar el agro argentino, (259-283). Bs. As.: Eudeba.

Arceo, Nicolás (2010). El rol del sector agropecuario pampeano en la economia argentina. 1960-2007. Tesis de doctorado en Ciencias Sociales. Bs. As.: FLACSO.

Aronskind, R. y Vommaro, G. (2010). Campos de batalla. Las rutas, los medios y las plazas en el nuevo conflicto agrario. Buenos Aires: Prometeo Libros.

Barsky, O. y Gelman, J. (2005). Historia del agro argentino. Desde la Conquista hasta fines del siglo XX. Bs. As.: GrijalboMondadori.

Barsky, O. y Dávila, M. (2008). La rebelión del campo. Historia del conflicto agrario argentino. Bs. As.: Sudamericana.

Basualdo, E. y Khavisse, M. (1994). La gran propiedad rural en la provincia de Bs. As. Desarrollo Económico 34 (134), 197-216.

Basualdo, Eduardo (1996). Los grupos de sociedades en el agro pampeano. Desarrollo Económico, 36(143), 807-828.

Basualdo, Eduardo (2006). Estudios de historia económica argentina. Desde mediados del siglo XX a la actualidad. Bs. As.: Siglo XXI editores.

Basualdo, E. y Arceo, N. (2009). Características estructurales y alianzas sociales en el conflicto por las retenciones móviles. En Arceo, N. et al. (Ed). La crisis mundial y el conflicto del agro (pp. 51-83). Bs. As.: Editorial La Página.

Bisang, Roberto (2007a). Apertura económica, innovación y estructura productiva: La aplicación de biotecnología en la producción agricola pampeana argentina. Bs.As. Documento inédito.

Bisang, Roberto (2007b). El desarrollo agropecuario en las últimas décadas: ęvolver a creer? En Anlló, G. et al. (Ed.). Crisis, recuperación y nuevos dilemas. La economía argentina 2002-2007 (pp. 187-260). Bs. As.: CEPAL. 
Boveri, Silvia y Lozada de Palma, Flora (1994). La creación de la Sociedad Rural Argentina. Realidad Económica, 125, 105-123.

De Imaz, José Luis (1964). Los que mandan. Buenos Aires: EUDEBA.

Dossi, Marina (2009). La acción colectiva de la Unión Industrial Argentina en el período 1989-2002. Un análisis desde su dinámica organizativa-institucional. Documentos de investigación social, Na 10 . Recuperado de http://www.u nsam.edu.ar/institutos/idaes/docs/DocIS_10_Dossi.pdf

Etchemendy, Sebastián (2015). La economia politica del neoliberalismo: empresarios y trabajadores en América Latina, España y Portugal. Bs.As.: Eudeba.

Etchemendy, Sebastián (2001). Construir coaliciones reformistas: la política de las compensaciones en el camino argentino hacia la liberalización económica. Desarrollo Económico, 40, Na 160, 675-706

Ferrer, Aldo (1986). La economia argentina. Bs. As.: FCE.

Gallo, E. y Cortés Conde, R. (1986). La república conservadora. Bs. As.: Hyspamérica.

Gerchunoff, P.y Torre,J.C. (1996). La política de liberalización económica en la administración de Menem.Desarrollo Económico, 36(143), 733-768.

Ghezán, G., Mateos, M. y Elverdín, J. (2001). Impacto de las politicas de ajuste estructural en el sector agropecuario y agroindustrial: el caso de Argentina. Santiago de Chile: Cepal. Serie Desarrollo Productivo 90.

Giarraca, N. y Teubal, M. (2010). Del paro agrario a las elecciones de 2009: tramas, reflexiones y debates. Buenos Aires: Antropofagia.

Gras, C. y Hernández, V. (2009). La Argentina rural. De la agricultura familiar a los agronegocios. Bs. As.: Biblos.

Gras, C. y Hernández, V. (2013). El agro como negocio. Producción, Sociedad y Territorios en la globalización. Bs. As.: Biblos.

Gras, C. y Hernández, V. (2016). Radiografía del nuevo campo argentino. Del terrateniente al empresario transnacional. Bs. As.: Siglo XXI.

Gras, Carla (2007). Apuntes sobre la construcción identitaria de un nuevo empresariado en el agro argentino. Trabajo presentado en V Jornadas Interdisciplinarias de Estudios Agrarios y Agroindustriales, Facultad de Ciencias Económicas, UBA. Bs. As. Resumen recuperado de: https://www.dropbox.com/sh/tgq8sptenkjk0ka/AAA6V 540lRM39YfLgNaP-tcxa?dl=0.

Gras, Carla (2009). El nuevo empresariado agrario: sobre la construcción y los dilemas de sus organizaciones. En Gras et al. (Ed.). La Argentina rural. De la agricultura familiar a los agronegocios (pp. 215-236). Bs. As.: Biblos.

Gras, Carla (2010). Elites rurales contemporáneas: cambio tecnológico, liderazgo empresarial y acción política en la Argentina sojera. Ponencia presentada en Taller El Bicentenario de la independencia y la(s) democracia(s) en América Latina. Berlín, Alemania.

Heredia, Mariana (2003). Reformas estructurales y renovación de las elites económicas en Argentina: estudio de los portavoces de la tierra y del capital. Revista Mexicana de Sociología, Año 65, № 1, Enero-Marzo, 77-115.

Hernández, Valeria (2005). Nuevos actores en el paisaje rural argentino: mercado, conocimientos e institucionalidad. Ponencia presentada en Coloquio internacional Trabajo, conflictos sociales e integración monetaria: América Latina en una perspectiva comparada. Los Polvorines, Bs. As.: Universidad Nacional de General Sarmiento.

Hernández, Valeria (2007). El fenómeno económico y cultural del boom de la soja y el empresariado innovador. Desarrollo Económico, 47(187), 331-365.

Hora, Roy (2002). Los terratenientes de la pampa argentina. Una historia social y politica, 1860-1945. Bs. As.: Siglo Veintiuno Editora Iberoamericana.

Hora, Roy (2005). La burguesia terrateniente. Argentina 1810-1945. Bs. As.: Capital Intelectual. Colección Claves para Todos.

Hora, Roy (2010). La crisis del campo del otoño de 2008. Desarrollo Económico, 50(197), 81-111.

Lattuada, M. y Nogueira, M. E. (2011). Capacidades estatales y políticas públicas. Una propuesta para el abordaje de las políticas agropecuarias en la Argentina contemporánea (1991-2011). Estudios Rurales. Publicación del Centro de Estudios de La Argentina Rural, 1(1), 30-54. 
Marcelo Oscar Panero. La representación de intereses de la cúpula del sector agropecuario. La Soc...

Lattuada, Mario (2006). Acción colectiva y corporaciones agrarias en la Argentina. Transformaciones institucionales a fines del siglo XX. Bs. As.: UNQ.

Levitsky, Steven (2005). La transformación del justicialismo. Del partido sindical al partido clientelista, 1983-1999. Bs. As.: Siglo XXI Editora Iberoamericana.

Lissin, Lautaro (2010). La Federación Agraria hoy: El campo argentino en discusión. Bs. As.: Capital Intelectual. Colección Claves para Todos.

Lodola, A. (2008). Contratistas, cambios tecnológicos y organizacionales en el agro argentino. Santiago de Chile: CEPAL.

Martínez Nogueira, Roberto. (1988). Las organizaciones corporativas del sector agropecuario. En Barsky, O et al. La agricultura pampeana. Transformaciones productivas y sociales (pp.295-322). Bs. As.: FCE, IICA, CISEA.

Murillo, M. V. (1997). La adaptación del sindicalismo argentino a las reformas de mercado de la primera presidencia de Menem. Desarrollo Económico, 37(147), 419-446.

Murmis, M. y Murmis M. R. (2012). El caso de Argentina. En Soto Baquero, F. y Gómez, S. Dinámicas en el mercado de la tierra en América Latina y el Caribe. Concentración y extranjerización, (pp. 15-58). Recuperado de: http:/ /www.fao.org/3/i2547s/i2547s.pdf.

Murmis, M. y Portantiero, J. C. (2004). Estudios sobre los origenes del peronismo. Bs. As.: Siglo XXI editores.

Muro de Nadal, M. (2009). El discurso y la práctica. Las complejas relaciones entre la Sociedad Rural Argentina y el gobierno del Dr. Menem. Documentos del CIEA (4), 185-219.

Newton, Jorge (1966). Historia de la Sociedad Rural Argentina. Bs. As.: Goncourt.

O' Donnell, Guillermo (1978). Notas para el estudio de la burguesía local, con especial referencia a sus vinculaciones con el capital transnacional y el aparato estatal. Estudios Sociales (12), 1-43.

Offe, Claus (1981). La atribución de un estatus público a los grupos de interés: observaciones sobre el caso de Alemania Occidental. En S. Berger. La organización de los grupos de interés en Europa Occidental. El pluralismo, el corporativismo y la transformación de la política (pp. 155-197). Madrid: Ministerio de Trabajo y Seguridad Social.

Palomino, Héctor (1995). Quiebres y rupturas de la acción sindical: un panorama desde el presente sobre la evolución del movimiento sindical en Argentina. En C. Acuña. La nueva matriz política argentina (pp. 203-229). Bs. As.: Nueva Visión.

Palomino, Mirta (1987). Las entidades agropecuarias. En Nun, J. y Portantiero, J. C. Ensayos sobre la transición democrática argentina (pp. 195-224). Bs. As.: Puntosur.

Palomino, Mirta (1988). Tradición y poder: la Sociedad Rural Argentina (1955-1983). Bs. As.: CISEA. Grupo Editor Latinoamericano.

Panero, Marcelo (2013). La representación de los sectores dominantes del agro en debate. La Sociedad Rural Argentina. En Gras, C. et al. (Ed.). El agro como negocio. Producción, sociedad y territorios en la globalización (pp. 323-345). Bs. As.: Biblos.

Panero, M. O. (2017). La representación de intereses de la cúpula del sector agropecuario: la Sociedad Rural Argentina: ¿declive o permanencia? Tesis de Doctorado. Universidad Nacional de San Martín. Recuperada de: http://bit.ly /2gq4puv00\&a $=\mathrm{d} \& \mathrm{c}=$ coltesis\&srp $=0 \& s \mathrm{srn}=0 \& \mathrm{cl}=$ search\&d=HASH01d $96 \mathrm{c} 33630 \mathrm{fe} 8 \mathrm{~d} 75858 \mathrm{bdb} 3$

Panero, Marcelo (2018). Pelea de grandes. La cúpula del agro durante el conflicto de 2008. En Panero, M. (Compilador). Actores, politicas públicas y conflicto agropecuario: A 10 años de la Resolución 125 (pp. 93-124). Villa María: EDUVIM.

Pereyra, Sebastián (2008). ¿La lucha es una sola?: la movilización social entre la democratización y el neoliberalismo. Los Polvorines: UNGS-Biblioteca Nacional.

Pitkin, Hanna (1985). El concepto de representación. Madrid: Centro de Estudios Constitucionales.

Pucciarelli, A. R., Castellani, A. G. (1998). Notas sobre la evolución de la noción de latifundio e hipótesis sobre la transformación de las grandes estancias en la época actual. Revista de ciencias sociales (9), 31-72. Recuperado de: http://ridaa.unq.edu.ar/handle/20.500.11807/1479.

Pucciarelli, Alfredo (1991). Evolución del proceso de desconcentración de la propiedad rural en la pampa bonaerense. 1920-80. Ruralia, 2, 57-93. 
Sidicaro, Ricardo (1982). Poder y crisis de la gran burguesía agraria argentina. En Rouquié, Alain (Comp). Argentina, hoy. Bs. As.: Siglo XXI editores.

Smith, Peter (1986). Carne y politica en Argentina. Buenos Aires. Hyspamérica.

Tarruella, Alejandro (2012). Historia de la Sociedad Rural Argentina. Bs. As.: Planeta.

Teubal, M. y Rodríguez, J. (2001). Neoliberalismo y crisis agraria. En Giarraca, N. et al. (Ed.) La protesta social en Argentina. Transformaciones económicas y crisis social en el interior del pais (pp. 65-116). Bs. As.: Alianza editorial.

Torre, Juan Carlos (2003). Los huérfanos de la política de partidos. Sobre los alcances y la naturaleza de la crisis de representación partidaria. Desarrollo Económico, 42(168), 647-665.

Viguera, Aníbal (2000). Estado, empresarios y reformas económicas: en busca de una perspectiva analítica integrador. Zona Abierta, 90/91, 161-203.

Zemborain, Saturnino (1973). La verdad sobre la propiedad de la tierra en la Argentina. Bs. As.: Instituto de Estudios Económicos de la SRA.

\section{Notas}

1 Con esta denominación se hace referencia a aquellas instancias representativas de larga data y con presencia continuada en la representación de un sector.

2 Esta delimitación temporal obedece, por un lado, a que en marzo de 1996 se liberó comercialmente la venta de las primeras semillas transgénicas en la Argentina. Esto, junto con los cambios económicos y político-estatales de los años 90, dio como resultado una transformación en la estructura productiva del agro argentino, lo cual tuvo impacto en la configuración de intereses y en las características de la representación sectorial. La fecha de finalización se debe al conflicto entre el gobierno nacional y las entidades representantes del agro, entre marzo y julio de 2008, cuyas características expresaron los mencionados cambios en la representación de intereses.

3 Para la obtención de los datos se recurrió a fuentes secundarias: Sistema Integrado de Información Agropecuaria (SIIA) del (ex) Ministerio de Agricultura, Ganadería y Pesca de la Nación, y del Instituto Nacional de Estadísticas y Censos (INDEC).

4 Los trabajos de Pucciarelli (1991) y Basualdo, Khavisse (1994) incluyen a quienes poseen 2.500 hectáreas o más. De Imaz (1964) tomó un criterio de 5.000 hectáreas o más. Basualdo (1996), por su parte, incluyó a los propietarios rurales con 20.000 o más hectáreas. Gras y Sosa Varrotti (2013), sin referirse a ellas como cúpula, se centran en las empresas que controlan más de 200.000 ha.

5 Esta base contiene información respecto de las entregas de granos realizadas por los productores a los compradores, la especie productiva entregada, la fecha de realización de la operación, el partido y provincia de origen y entrega del grano, y el peso bruto y neto de lo transferido. Más detalles en Panero (2017), anexo metodológico.

6 Informa sobre la cantidad de animales que posee el establecimiento y la provincia en que está ubicado. Más detalles en Panero (2017), anexo metodológico.

7 Para la producción agrícola, se tomaron los rendimientos productivos del año respectivo. Para la ganadería, se estimó la superficie en hectáreas a partir de la cantidad de ganado poseído, tomando como criterio 1 animal / 1 hectárea.

8 Las decisiones metodológicas respecto de las fuentes de información a emplear implican asumir ciertas limitaciones. En este caso, se aclara: a) Al tomar como criterio de inclusión/exclusión de la cúpula el número de hectáreas destinadas a la producción, se omiten las diferentes calidades que puedan poseer las tierras, las diferentes productividades y valuación económica. Asimismo, dicho criterio de inclusión/exclusión oculta también que, en muchos casos, la agricultura se hace en tierras de mejor calidad que la ganadería. La comparación de la cantidad de hectáreas destinadas a la actividad agrícola y la ganadera, sin considerar la diferente calidad de la tierra y sus distintos rindes, puede haber derivado en una sobreestimación de los productores ganaderos frente a los agrícolas. b) Las bases de datos empleadas corresponden a períodos diferentes. Pese a ello, se decidió analizarlas unificadamente para realizar una estimación, aproximada y exploratoria, de las características que presenta la cúpula agropecuaria de manera integral. c) Estas fuentes de datos sólo incluían información de las firmas con respecto a producción agropecuaria primaria, con lo cual se incluyó dentro de la cúpula sólo a aquellas firmas que cumplieran con la condición de destinar a la producción primaria al menos 10.000 ha, sin considerar los capitales que pudieran poseer en otro ámbito.

Aun a sabiendas de estas limitaciones, se decidió trabajar con estas fuentes debido a que brindan información que complementa la de otros trabajos anteriores (de Imaz, 1964; Chazarreta, Rosati, 2016; Basualdo, 1996; Gras, Sosa Varrotti, 2013; Murmis y Murmis, 2011), a la vez que podrían suplir algunos de sus límites. Por un lado, relevan datos de un gran número de casos: 38.203 productores de soja, 20.236 de trigo, así como la totalidad de los productores ganaderos 
que declararon animales. Asimismo, a diferencia de los trabajos centrados sólo en una provincia, estas bases cuentan con información acerca de la totalidad del territorio nacional. Por último, a diferencia de los resultados de los censos agropecuarios, cuya unidad de análisis la constituyen las explotaciones agropecuarias, las bases de datos empleadas aquí permiten considerar como una sola firma a más de una unidad productiva y/o explotación.

9 En este documento se consignan todas las actividades llevadas a cabo por los miembros de la entidad (Comisión Directiva, diferentes comisiones especializadas, socios, etc.), como reuniones, viajes, eventos, celebraciones, publicaciones, entre otras. Se analizaron todos los números comprendidos entre los años 1996 y 2008.

10 Se realizaron en total 34 entrevistas: 7 a grandes productores y 1 a un empleado de otra gran empresa, 8 a dirigentes de SRA y 5 a miembros de entidades de productores asociadas a SRA, 3 a dirigentes de FAA y CRA, 5 a especialistas agropecuarios, 2 a periodistas de medios de alcance nacional y 1 de alcance regional, así como 2 entrevistas a funcionarios nacionales del área agropecuaria.

11 Hacia la campaña 98/99 la soja transgénica representaba dos tercios de la superficie sembrada con este cultivo, el $85 \%$ en 2000/01 y alcanzó el $100 \%$ en la campaña 2002/03 (Bisang, 2007b).

12 Este corrimiento fue posibilitado, en buena medida, por la incorporación de nuevas razas y/o por el cruzamiento con razas más resistentes a las condiciones climáticas de estas tierras.

13 La zona central del país (Bs As., Santa Fe, Entre Ríos, Córdoba, La Pampa) registró un descenso de 5 puntos porcentuales en su participación sobre el total de las existencias vacunas, pasando de representar el $77 \%$ en 1996 al $72 \%$ en 2008. En contraste, la zona Litoral-NEA (Chaco, Corrientes, Formosa, Misiones) acrecentó su participación en 2,3 puntos porcentuales y el NOA (Salta, Jujuy, Santiago del Estero, La Rioja, Catamarca y Tucumán) creció 1.61 puntos porcentuales (Datos Encuesta Nacional Agropecuaria, MAGyP - INDEC).

14 Dados los posibles sesgos mencionados en la nota 8, punto a, esta información es confiable respecto de mostrar el grado de especialización productiva. No obstante, se sugiere relativizarla en lo que refiere a la distribución por rubro de actividad agropecuaria.

15 Buenos Aires, Córdoba, Chaco, Chubut, Corrientes, Entre Ríos, Formosa, Jujuy, La Pampa, Salta, Santiago del Estero, Santa Fe, San Luis, La Rioja, Misiones, Santa Cruz y Tucumán.

16 El vigente fue sancionado el 28/09/2000 y aprobado por Resolución N 537 de la IGJ el 26/06/2002.

17 Integrada por el Presidente; el Vicepresidente 1ro; 14 Vocales Generales Titulares; 14 Vocales Titulares por Distrito; 2 Vocales Titulares por el Consejo Institucional; 2 Vocales Titulares por el Consejo Federal; 2 Vocales Titulares por los Socios Adherentes.

18 Conformada por el Presidente; el Vicepresidente 1ro; el Vicepresidente 2do; 2 secretarios; el Tesorero; el Protesorero; el Director de Anales, Boletín y Prensa; el Director de Biblioteca; el Director del Instituto de Estudios Jurídicos; el Director de Registros Genealógicos; el Director del Instituto de Estudios Económicos; el Director de Exposiciones y Director de Acción Gremial.

19 Relevamiento propio a partir de datos contenidos en la página de Internet de SRA, en 2010. Se tomó este año por ser el más próximo a 2008 a cuya información institucional se pudo acceder.

20 Esta caracterización de los dirigentes de SRA fue elaborada, principalmente, sobre la base de información cotejada entre el listado de dirigentes y datos de los integrantes de la cúpula. Dado que esto puede verse afectado por el sesgo manifestado en la nota 8, dichos rasgos se corroboraron con información obtenida en entrevistas a dirigentes de la SRA.

21 Se consideró, para cada dirigente, en cuántas provincias figuraba un establecimiento donde desarrollaba una actividad productiva. Esto condujo a que el número de establecimientos no coincidiera con la cantidad de personas, dado que algunos de ellos poseen establecimientos en más de una provincia. Por ello, la información se consigna en porcentajes.

22 Las mencionadas actividades fueron relevadas a partir de la lectura de los Suplementos de la revista Anales de SRA, y del diario La Nación. Para el abordaje y posterior análisis de estas acciones, i) se seleccionaron aquellas que aparecieron reiteradamente y merecieron un seguimiento por parte de la entidad; ii) se excluyeron aquellas que aparecieron una sola vez y no fueron retomadas en ningún otro momento del período; iii) se agruparon las acciones que tenían el mismo disparador o los mismos motivos. Dada la extensión de este artículo, sólo se realizará una síntesis del accionar desarrollado. Un tratamiento exhaustivo en Panero (2017).

23 No se desconoce que los intereses que la entidad defiende pueden ir más allá de los públicamente manifestados. No obstante, aquí se consideran solamente aquellos por los que aboga públicamente ya que puede obtenerse información acerca de ellos, lo que no ocurre con los que se defienden a "puertas cerradas".

24 El tratamiento de este conflicto amerita un desarrollo más extenso y exhaustivo, que excede las posibilidades de este artículo. Ver Panero (2018); Aronskind y Vommaro (2010); Barsky y Dávila (2008); Basualdo y Arceo (2009); Giarraca y Teubal (2010).

\section{BY-NC-SA}

